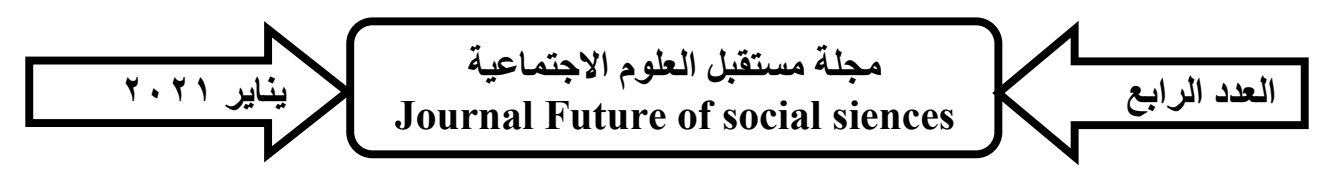

\title{
العشور في المسيحية وحقوق الإنسان
}

\author{
إعداد \\ الباحث / مهايكل إدوارد
}

باحث دكتوراه بقسم علم الإجتهاع بكلية الأداب جامعة حلوان 


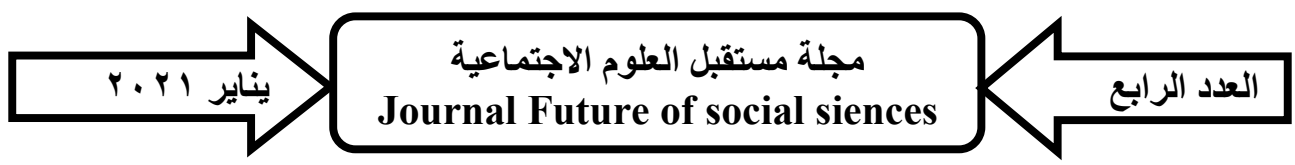




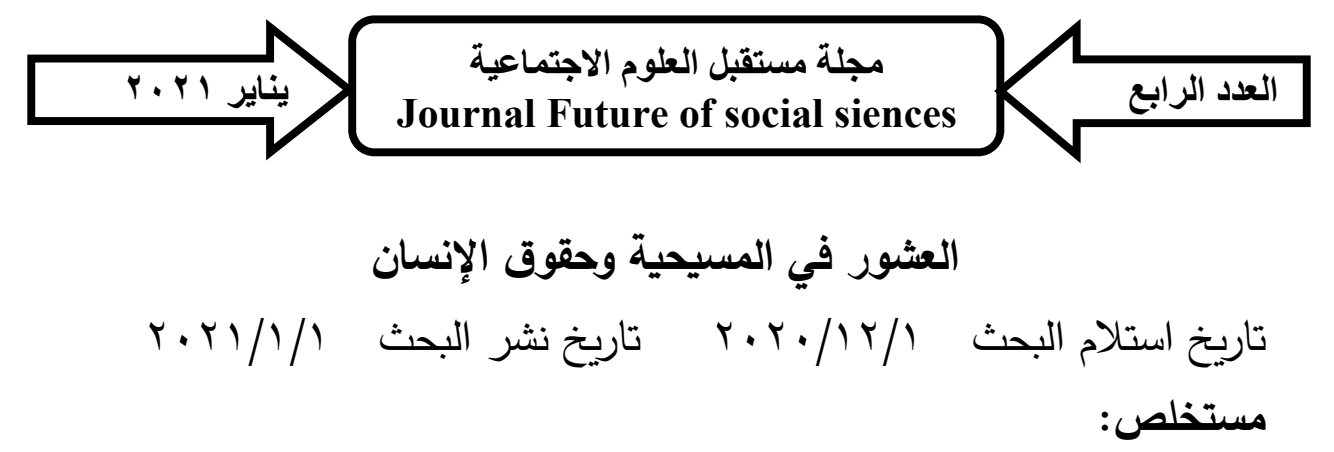

تحاول تلك الدراسـة تحديد معني العشور في المسيحية والتركيز علي العشور أيضا فيما يتعلق بحقوق الإنسان، حيث إن لدى البعض مفهوما أن ما

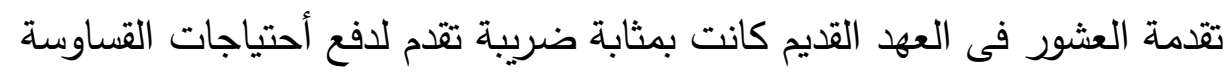
والنظام الكنسى، وأن العهد الجديد لا يجبر أو حتى يقترح على المسيحيين أن يكون لديهم نظام يقنن العشور ، كما تدل الكلمة ايضا على الامانة الثخصية في لئل الممارسات الدينية اليهودية المتعلقة بالصلاة والزكاة (الصدقة) والصوم اذ اوصى الصى المسيح تلاميذه بالعمل بها او بالدعوة لها، ويقابل العشور عند المسيحيين الزكاة الكلمات المسلمين التى تعد أصل من أصول الدين الإسلامى. العشور - حقوق الإنسان - المسيحية.

\section{Abstract:}

This study tries to define the meaning of tithing in Christianity and focus on tithing also with regard to human rights, as some have an understanding that what was offered tithing in the Old Testament was a tax paid to meet the needs of priests and the ecclesiastical order, and that the New Testament does not compel or even suggest to Christians that They have a system that codifies the tithe, and the word also indicates personal honesty in Jewish religious practices related to prayer, zakat (charity) and fasting, as Christ recommended to his disciples to work with it or to call for it, and the tithe for Christians corresponds to zakat for Muslims, which is one of the origins of the Islamic religion.

Key words: Ushur - Human Rights - Christianity. 


\section{العدد الرابع \\ العشور في المسيحية وحقوق الإنسان}

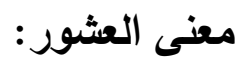

العشـور هـو الممارسـة الثـائعة فـى الكنيسـة، وهـو المـذهب الذَى يـتم

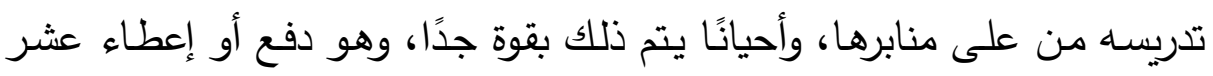

(Peper, 2010, p1). الدخل إلى الكنيسة

ويعد تقديم العشور مبدأ من مبادىه العهد القديم. فالشريعة كانت تحتم

على شعب اسرائيل إعطاء • (\% من دخلهم ومنتجات حقولهم الى المعبد

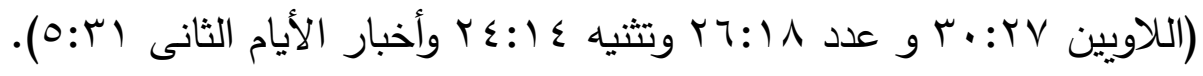

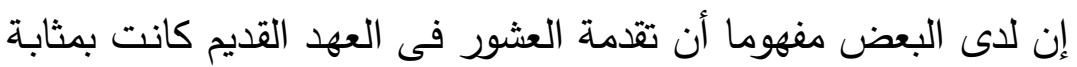

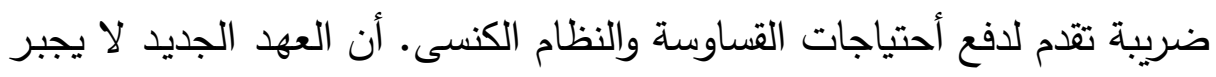

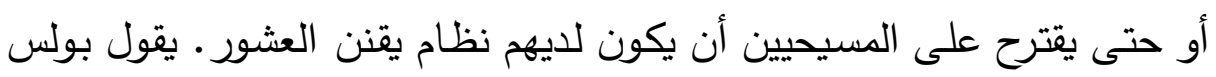

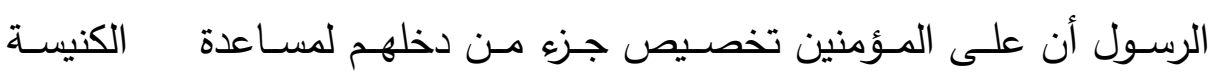

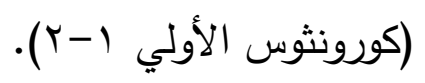

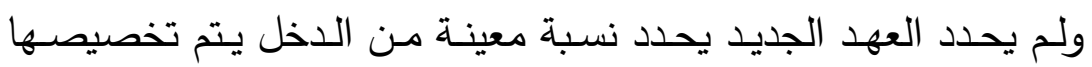

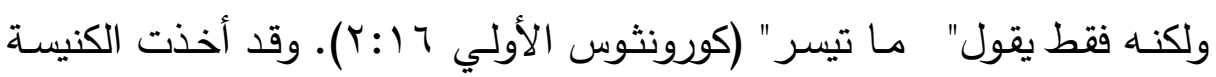

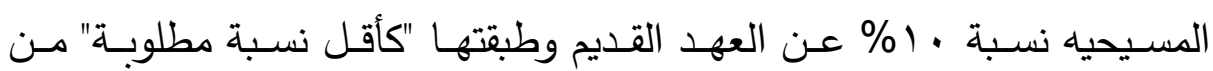
المسيحي فى العطاء. ولكن لا يجب على المسيحيين أن يشعروا دائما بأنهخ

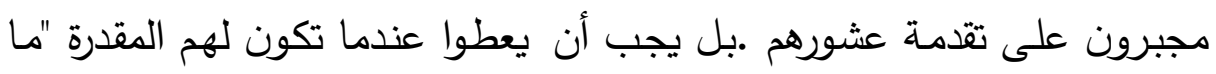

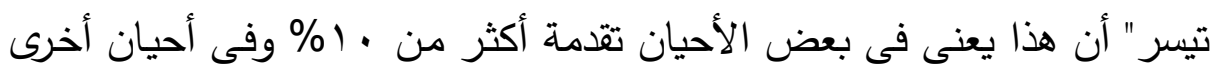

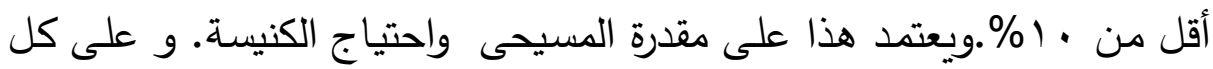

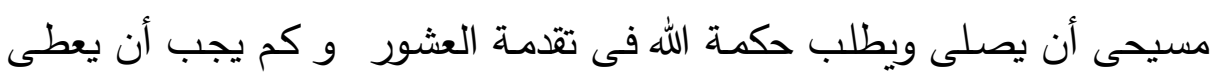
(يعقوب (0:1) ـ فالكتاب المقدس يقول "كل واحد كما ينوى بقلبه ليس عن حزن أو أضطرار لأن المعطى المسرور يحبه الله"(كورونثوس الثانية:9) 


\section{| العدد الرابع}

(WWW.GOTQUESTIONS.ORG/ARABIC)

كيف تقدر العشور : (Peper, 2010,p1)

يرى البعض أن العشور يكون من الدخل الإجمالى للمره، أى قبل أيـة

استقطاعات بما فى ذلك الضرائب

ويرى البعض الآخر أن العشر يقدر على صـى الدخل الذى يحصل

عليه المرو بعد الاستقطاعات

والبعض يرى أن العشر يقدر على الأموال التى تبقى مع المره فعليًا بعد

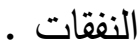

وقد ورد لفظ الصدقة والصدقات في انجيلي متى ولوقا، ويـاتي اللفظ

اليوناني للصدقة بمعنى " أجر" كثيرا في انجيل متى مرادفا لمعنى الصدقة.

كمـا تدل الكلمـة ايضـا على الامانـة الثخصية في الممارسـات الدينيـة

اليهودية المتعلقة بالصـلاة والزكاة (الصدقة) والصوم اذ اوصسى المسيح تلاميذه

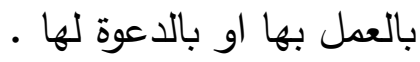

ايضـا تأتي كلمة الصدقة بمعنى المكأفاة كما جاء في انجيل لوقا (ب:

rr- §ץ) وايضا يميل انجيل لوقا الى نزعة تصدقية متثددة في مكان اخر من

انجيليه اذ يقول: " بيعوا ما تملكون وتصدقوا، اتخذوا لانفسكم اكياسـا لا تبلى،

وكنزا في السماوات لا ينفد، حيث لا يقرب سارق، ولا يبلى سوس، لانـه حيث

يكون كنزكم هنالك يكون قلبك ايضـا ـ وقال متى:" اذا اردت ان تكون كاملا،

فاذهـب وبـع مالك ـ واعط الفقراء لك كنزا في السماء (متى 9 ( - (r) وايضـا

يعطي مرقس امثال توضحية لمعنى الصدقة اذ يروي مثال الرجل الغني الذي

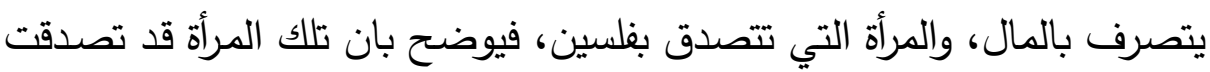
بما تملكه حقا، في حين ان الغني تصدق بفضله رزقه وبقي رأس ماله محفوظا.

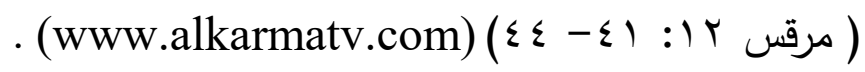




\section{| العدد الرابع}

ولذلك يحصر الكتاب المقدس مفهوم الصدقة بصفات محدودة منها: الانفاق على المساكين، فمن اعطاهم شيئا خيره دائم الى الابد اعطاء الصدقة بنيَة صادقة لله يفضل اعطاؤها سرا وليس امام الناس • وقد ورد لفظ (الصدقة والصدقات) في إنجيلي متى ولوقا فقط، بينما ورد ذكر (العشـور ) في الأناجيـل النصـرانية كضــرب أمثال للعظـة، إذ ذكـرت أن وأن

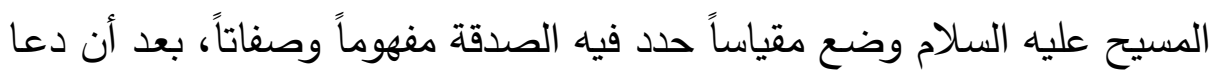
إلى الخلاص من رق العبودية كما شجب تصرفات اليهود اللا أخلاقية ودعا إلى لصى إحلال القيم الأخلاقية النابعة من النية الصادقة المفعمة بالحقيقة من دون رياء،

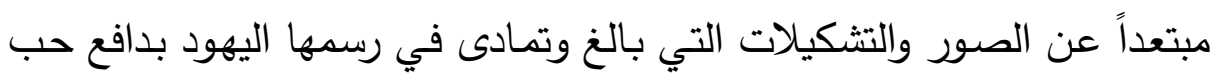
الظهور والمراء أمام الناس. ولا يوجد مقدار محدد ولا نصـاب محدد بـل هناك مواعظ للترغيب في البذل وترك المال كاملاً.

ويؤمن النصارى أن فرض (العشور) مفروض عليهخ كما هو الحال عند اليهود، إذ تؤخذ العشور من الأموال النقدية وغير النقدية فتؤخذ العشور من بكر لهن الغلات الزراعية ومن نتاج الحيوانات وتعطى لمستحقيها من الفقراء والمساكين، إلا أنهم يرون أن إعطاء العشر بهذا التحديد لا يقصد منه إلا الإيفاء التام بهذاء الواجب أمـام الله سبحانه، فالنصراني لم يعد يلتزم بنسبة العشور التي تفرضها التوراة وإنما أصبحت الصدقات مفتوحة دون تحديد نسبة ما وهي بذلك تتداخل عندهم مـع الصدقة الذاتية للفرد فلا يحصل بينهما التمييز وربما بمرور الزمن تضمحل الفريضة وتبقى الصدقة لأن الإنسان ميال إلى التصدق على الفقراء في أوقات غير محددة بالكم والكيفية كما هو الحال في العشور • (المطرود، ص^) 


\section{مجلة مستقبل العلوم الاجتماعية 1 Journal Future of social siences}

\section{مجالات العطاء:}

1- عطاء مـادي:هو عطاء المال والمقتنيات سواء عشور او بكور او نذور ،

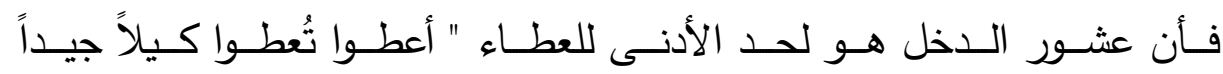

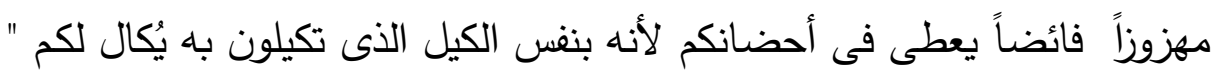

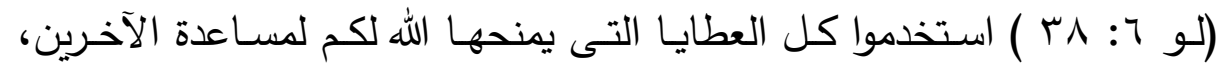
أعطوا أحسن ما عندكم لكل من هو محتاج وكونوا معطين أسخياء، كبار فى

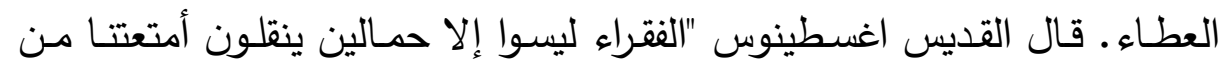

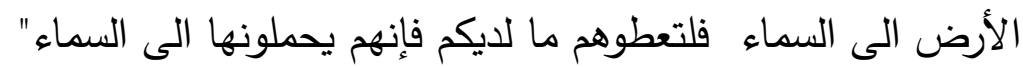

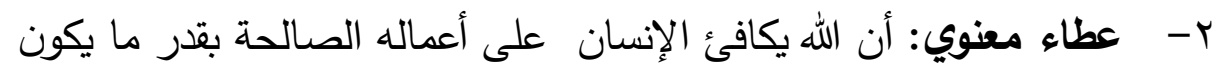

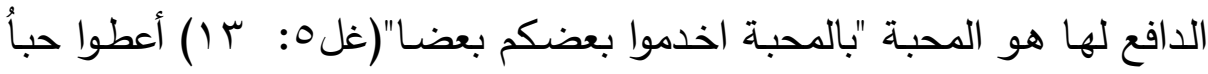

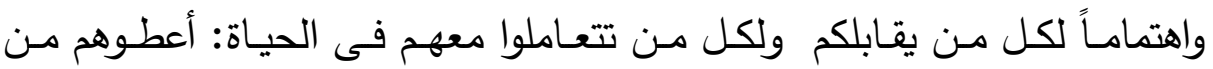
صلواتكم من أوقاتكم من حبكم واهتمامكم ومن نفوذكم ..ثم بعد ذلك من خيرات العالم وأمواله. قال القديس انطونيوس " العبرة ليست فى العطاء وإنما فى السرور فى العطاء، وان لم يوجد إمكانية للعطاء فالحنو (الحب) وحدة كاف لمن نحب".

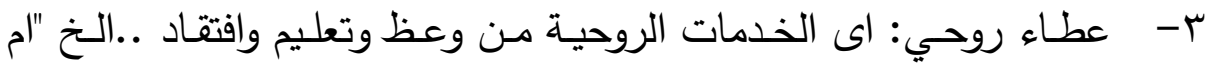
خدمة ففي الخدمة ام المعلم ففي التعليم ـ ام الواعظ ففي الوعظ المعطي فبسخاء

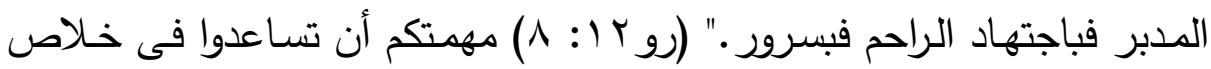

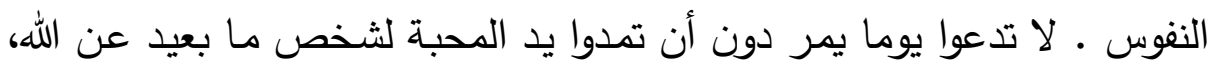
قدموا ولو مجرد ملاطفة، رسالة، زيارة ساعدوا بطريقة ما. قال القديس مكاريوس "إتضعوا لإخوتكم واخدموهم حسب قوتكم لأجل المسيح لتنالوا منه جزاء."(دميان،

ويقابل العشور عند المسيحيين الزكاة عند المسلمين التى تعد أصل من أصول الدين الإسلامى، وهى فى الإسـلام نظام اقتصادى عام يحكم نشاط رأس لرهاه 


\section{العدد الرابع}

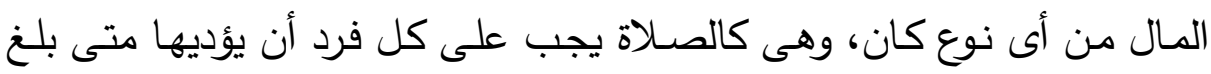
عنده النصـاب المقرر شرعًا، ويجب على الدولة أن تجيبها لأنها فريضـة يكفر

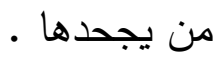

وقد روى عن الرسول ححم أنه قال " إن الله فرض على أغنياء المسلمين

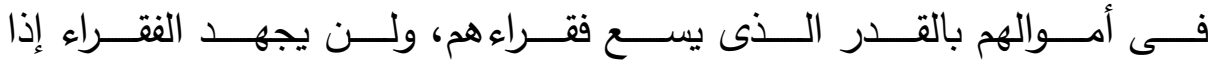
مــا حـاعوا وعـروا إلا بمـا يصـنـع أغنيـاؤهم، ألا إن الله يحاسـبهم حسـلبًا شـديدًا

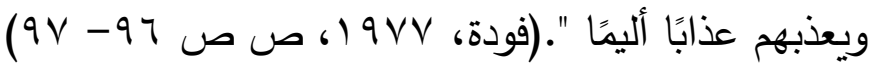
وكما أن الزكاة تطهر نفوس الأغنياء من الثح والبخل فهى تطهر نفوس الفقراء من الحقد والحسد والبغض، وتطهر المال من الثر الذى يشوبه ببقاء حق

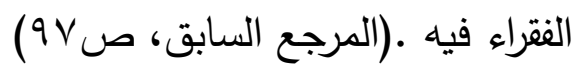
كما تؤدى الزكاة إلى انتشار التكافل الاجتماعى ويقصد بمصطلح التكافل

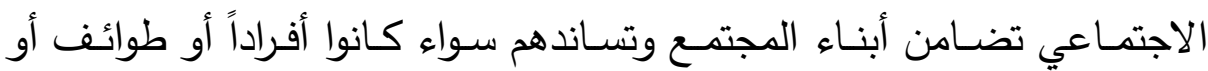

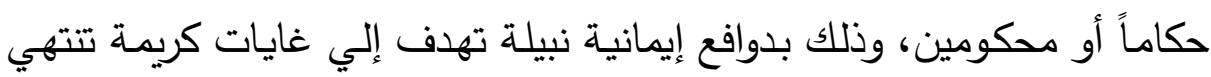

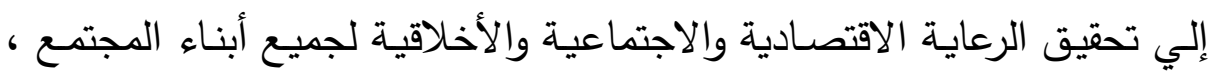
وذلك بتـوفير الاحتياجـات الأساسـية مـن مأكل ومشـرب ودواء وكسـاء وتعليم وليه بالإضـافة إلـي كـل مـن يحـاول خـرق سفينة المجتمع كـالمخربين والمحتكرين

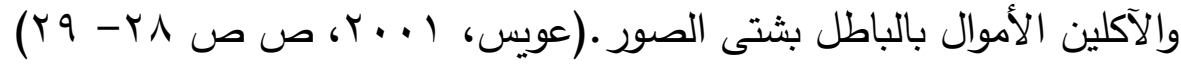
وقد شرع الإسلام مبدأ التكافل الاجتماعي بل جعله من فرائض الإسلام ،

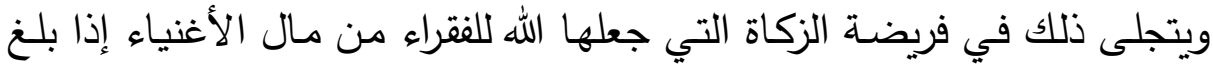

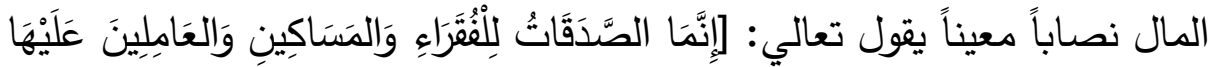

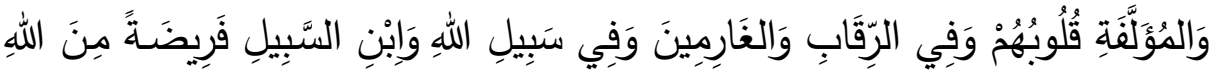

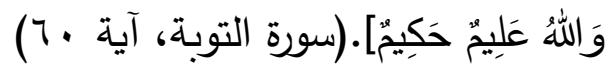




\section{| العدد الرابع}

فقد أوضحت الآية الكريمة الأشخاص الذين تجب لهم الزكاة. وذلك حتى

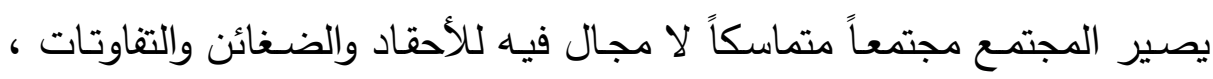
وحتى لا يهلك أناس لكثرة طعامهم ولا يهلك أناس لخلو بطونهم. العشور والتقليل من الفقر وحماية حقوق الإنسان:

إن التفاوت الكبير يعوق الحد من الفقر ولذلك يجب أن يهتم واضعواله الإسله السياسة على تقليل الفقر ، حيث لا ينبغى أن نقبل بسياسات توزيع تضع عبء مستويات المعيشة الأدنى والأطول مدى على عاتق الفقراء، وتتطلب زيادة سرعة

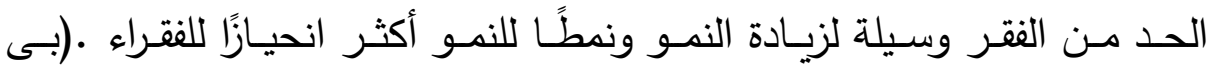

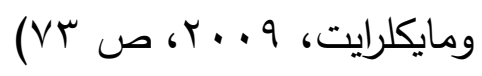

وتشير تقارير الأمم المتحدة لعام . ... ب إلى أن نصف سكان العـالم

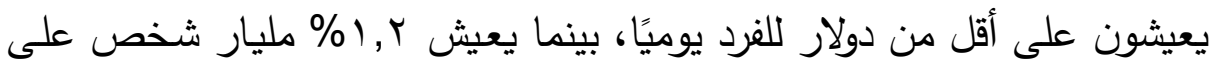
دولار واحد يوميًا، كما يبلغ عدد الذين يعيشون تحت خط الفقر فى العالم العربى

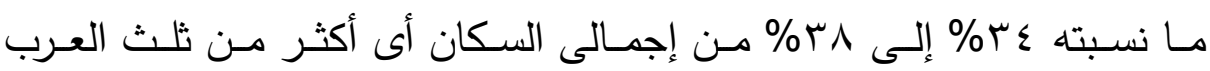

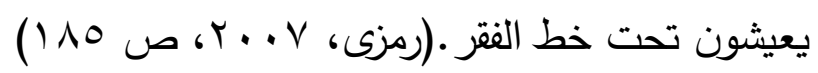

وتصل نسبة متوسط الدخل الفردى فى الدول النامية إلى الدول المتقدمة 1: 10 تقريبًا، هذا ويرجع انخفاض متوسط دخل الفرد فى الدول النامية لضآلة الناتج القومى فيها بوجه عام •

وهذا التفاوت الصـارخ فى توزيـع الدخل القومى يكون عقبـة هامـة فى في سبيل تحقيق التنميـة، حيث يكون لـه مسـاوئ كبيرة من الوجهتين الاقتصـادية

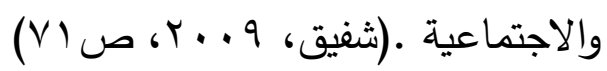

وتؤكد الاحصـائيات الخاصــة بالمنظمـات الدوليـة أن مشكلة الفقر فى الفى تدهور إذ تشير الإحصائيات الصادرة عن منظمة الفاو إلى أن هناك . بممليون شخص فى العالم يشكلون ما نسبته ؟ ( \% من سكان العالم انحدر بهم الحال من 


\section{| مجلة مستقبل العلوم الاجتماعية}

الفقر إلى حالة الجوع، ومن المتوقع أن يتضـاعف عدد الذين يقبعون تحت خط

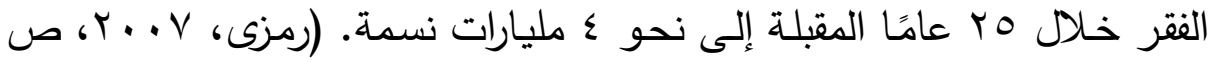
(1)0

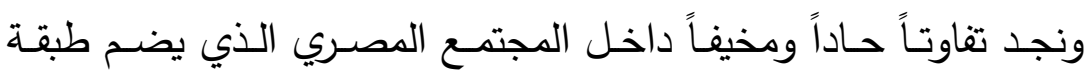

الأثرياء والطبقة الوسطي والطبقة الدنيا.

الطبقة العليا ويقدر بعض الخبراء أن الدخل السنوي لا يقل في المتوسط واء

عن r مليون جنيه مصري في السنة وهي فئات لها نمطها المعيشي المتميز من حيث أنماط السكن والتعليم والتسوق والترفيه. بل إن بعضها يتجمع في مناطق محدة من القاهرة الكبرى مثل التجمـع الخامس والمنتجعات ، ويبلغ عدد الأسر

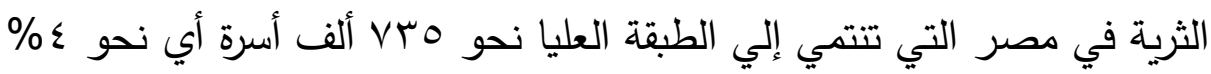
من إجمالي الأسر المصرية. وقد اتسم النمو الاستهلاكي لهذه الفئات بالإنفاق

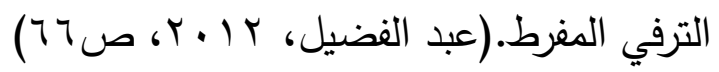
الطبقـة الـنيا: وهم سكان المناطق العشوائية الذين يعيشون في قاع المدينـة

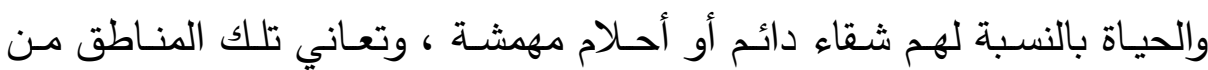
تدهور كبير في الخدمات التعليمية والصحية والترفيهية ، مما جعل سكان تلك المجتمعات عرضة للمشاكل الحادة.(المرجع السابق، ص ص 9 ـ - . ب) الطبقة الوسطي: وهي ليست طبقة متجانسة بل متعددة الشرائح والمراتب وأدت التغيرات وعمليـات التحـول الاقتصـادي والاجتمـاعي إلي تـأرجح وضـع الطبقـة الوسطي فضعف وضعها الاقتصادي والاجتماعي نتيجة لتتاقض أجورهم وزيادة الأسعار وإلغـاء الدعم وخصخصـة بعض الخدمات ، وترتب علي تدهور هذه الطبقة أن أصبح الملايين من أبنائها يعانون الخوف والقلق علي المستقبل مما أدي إلي ظهور الاغتراب وعدم الانتماء والانفصـال عن المجتمع مما نجم عنـه الخرافات وفساد وبلبلة خاصة بين الثباب فظهرت مشكلات وظواهر جديدة علي 


\section{العدد الرابع}

المجتمع مثل حالات التهور واللامبالاة وإدمان المخدرات والتسرع ، كما ظهرت

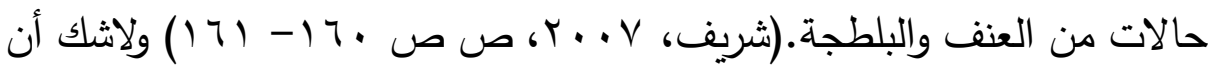
كل ذلك يـؤدى إلـى الاحتقــان فـى المجتمـع ويهـد الأمـن والسـلام والاسـتقرار المجتمعى، ولذلك فإن تقديم العشور يؤدى إلى الاستقرار والتكافل بين الأغنياء والفقراء، ويؤدى كذلك إلى حصول المهشين على حقوقهم مما يعود بالخير على الى لـى

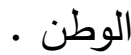

وتقوم الكنائس بدور كبير فى علاج مشكلة الفقر، فمحبة المسيح تلهم

المسيحيين ألا يهدأوا إزاء العنف وعدم المساواة، إن وجود الروح القدس يتجلى بـى فى التوق إلى العدالة، وهو الأمـر الذى يقلق كنائس أمريكـا اللاتينيـة وخاصـة الكنيسة الكاثوليكية فى البرازيل، فتحت وطأة فظائع الديكتاتوريات العسكرية فى السبيعنيات اضـرر قـادة الكنيسـة إلى التخلى عن الدور التـاريخى لمؤسستهر

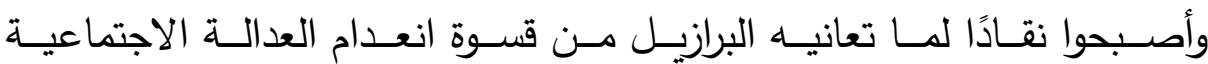
والاقتصـادية، وحولـوا كثيـرًا مـن الرهبـان والراهبـات مـن العمـل بـين الطبقـات

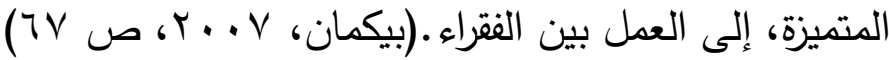
ويـرى قسم مـن المـؤرخين بأن الكنـائس الرسـية لـم تكن تدعم حقوق الإنسـان ، فالمسـاواة بين النـاس على الأرض بقيت محدودة وغريبة عن رجال

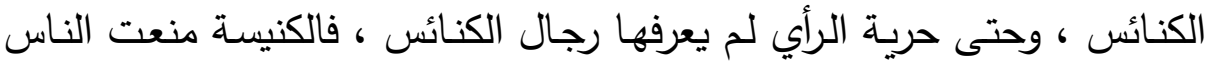
من الإبداء بآرائهر ، كما أنها استعملت العنف في شمال أوربا لتجبر الناس

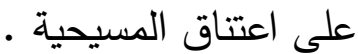

وكانت تعاليم المسيحية تعتمد على أن عيسى المسيح هو صلة الوصل بين الإله والمخلوقات ، ولهذه الأسباب كلها فإن الشخصية الإنسانية ، تستحق كثيرا من العناية وهذه الفكرة جاءت من الفلسفة اليونانية والمسيحية دعت إلى الى مساواة الجميع أمسام الله وكان إقبال العبيد عليها واسع لأنها دعت إلى تحريرهم 


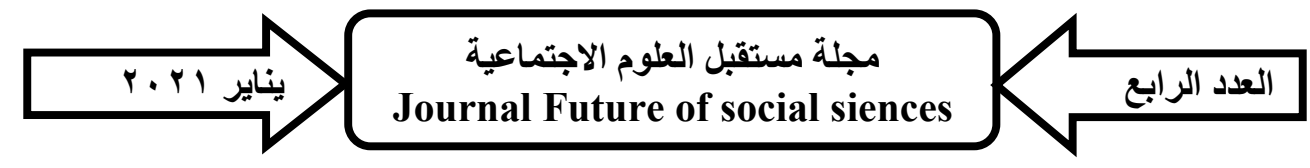

ولكن وللأسف صداها كان محدود ـ أما فيما يتعلق بالمبدأ الثاني وهو تحديد

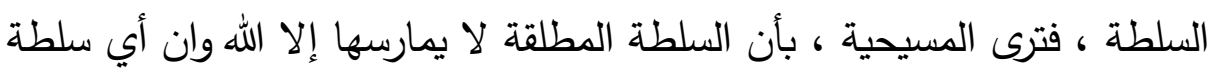
فوق هذه الأرض لا يمكن أن تكون سلطة مطلقة ،وترى أن أي سلطة إنسانية

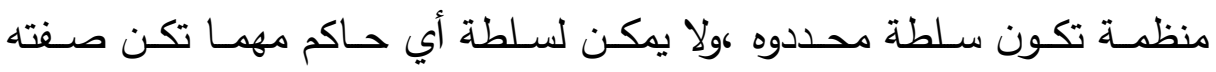
المطلقة، وهنـا ترى هذه الديانـة أن من حق الناس أن يثوروا على الحاكم إذا

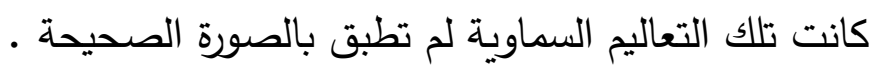

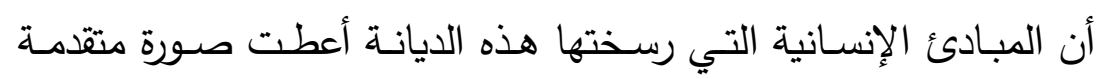

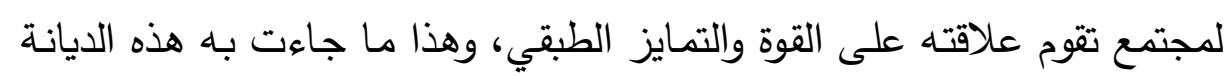

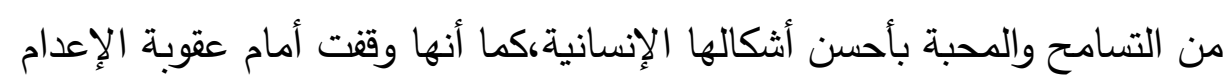
وعملت على وضـع تشريعات لحمايـة حقوق الإنسـان من تلك العقوبـات لكي

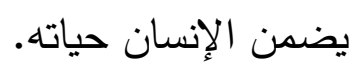

إن الدافع للعطاء لا ينبغي أن يكون هو انتظار الحصول على شئ ما في مقابل هذا العطاء، فمثل هذا الدافع قد يقودنا بسهولة إلى روح الجثح، وإلى لى إنى

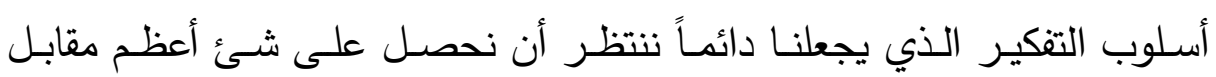
الثيء الأصغر الذي نقدمه. ينبغي أن يكون عطاؤنا نابعاً من دوافع الثكر لله دأنه

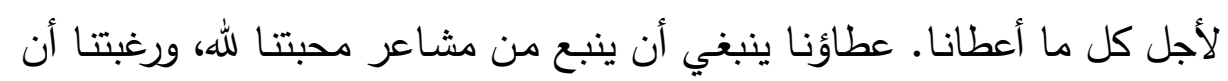
نرى عمل الله يزدهر وينتعش؛ حتى يمكن للآخرين أن يسمعوا رسالة الإنجيل

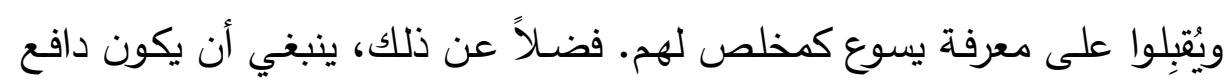

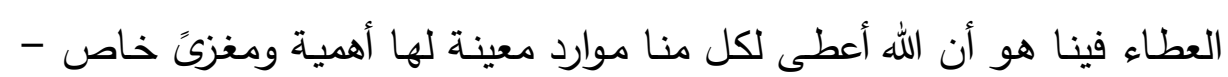

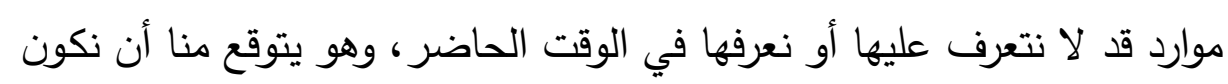

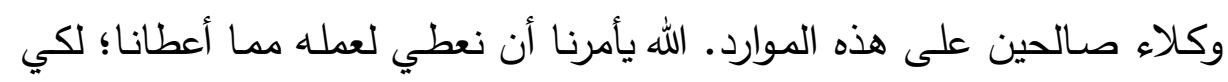
ننفذ الأشياء التي يريد الله تحقيقها على هذه الأرض. هده. 


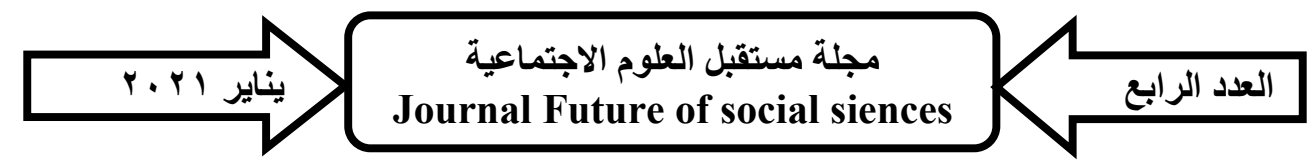

علينا إذاً أن نعطي بقلب شكور ، وبرغبة لأن نطيعه، و وباستعداد لأن

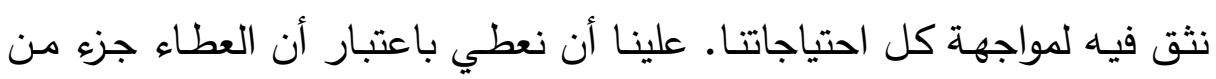

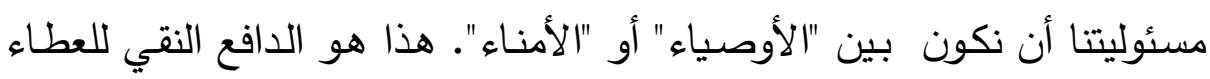

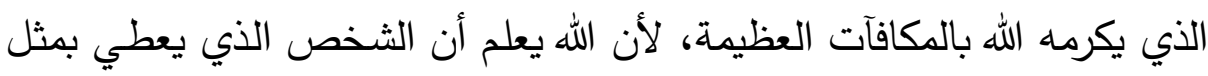
هذه الدوافع هو الثخص الذي يمكن أن يؤتمن على البركات المادية. 


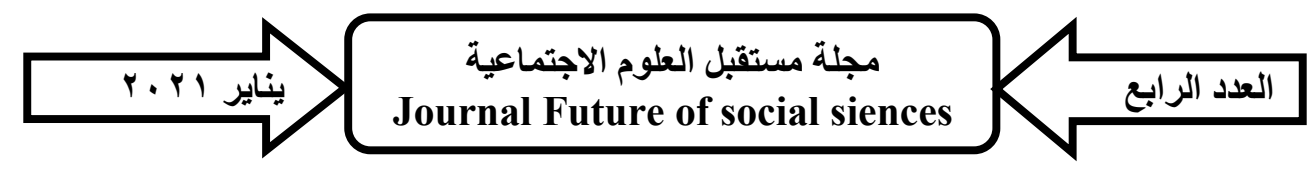

المراجع

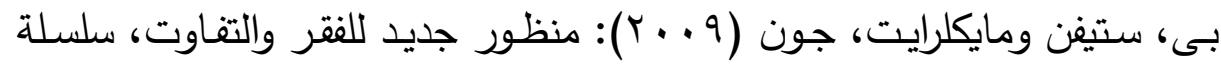

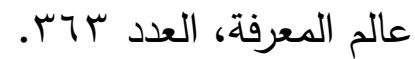

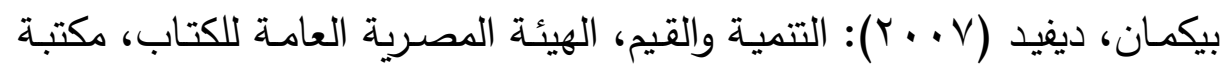
الأسرة. - مان ديفيد

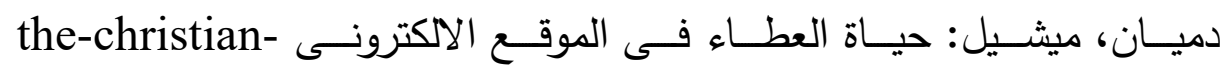

r. I $\varepsilon / \cdot V /$ life.blogspot.com/p/blog-page_28.html28

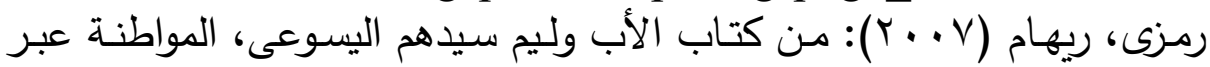

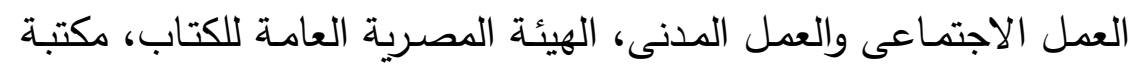

الأسرة، القاهرة.

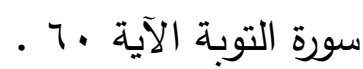

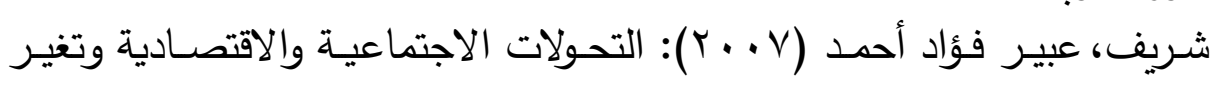

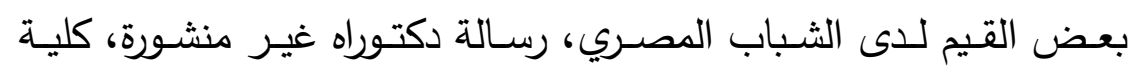

الآداب، جامعة المنوفية.

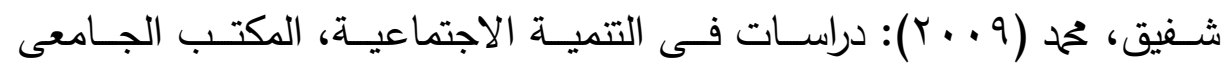
الحديث، الإسكندرية.

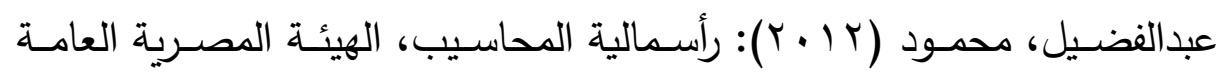
للكتاب، القاهرة.

عـويس، عبد الحليم (1 ( . ب): الإسـلام وتحديات العصـر، كتاب الجمهوريـة، القاهرة.

فودة، عبد الرحيم (9VV ( )): الدين عند الله، مجمع البحوث الإسلامية، القاهرة.

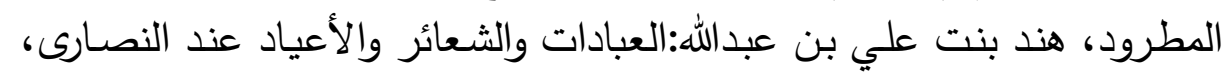

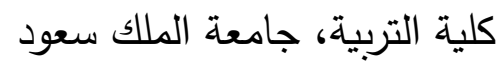

peper ditzel (2010): what the bible says about tithing and christian giving; minor revision.

PERER DITZEL (2010): WHAT THE BIBLE SAYS ABOUT TITHING AND CHRISTIANGIVINIG ;MINOR REVISION.

www.alkarmatv.com

WWW.GOTQUESTIONS.ORG/ARABIC 